\title{
IIa. Register over den anmeldte litteratur
}

(ordnet alfabetisk efter forfatter, udgiver eller titel).

\author{
Albeck, Gustav (ed.)
}

Grundtvigs Dag- og Udtogsbøger. (Chr. Thodberg). . . . . . . . . . . . . .

80 86-88 (96)

Bannwart, Claudio:

N. F. S. Grundtvig: De Levendes Land. (Kalender m. linoleumssnit). (W. Michelsen). . . . . . . . . $8593(103)$

Behrend, Harald og Lorchner, Norbert:

Geschichte und Gegenwart der Heimvolkshochschulen in Dänemark. (R. Skovmand). . . . . . . . .

Behrendt, Poul:

Viljens former. (Mogens Bjerring Hansen). . . . . .

Bodenstein, Eckhard:

Skolefrihed in Dänemark. (Vilh. Nielsen). . . . . . .

Bohn, Oluf (red.):

Fra modernisme til nymarxistisk kritik. (W. Michelsen).

71 120-121 (133-134)

Borum, Poul:

Digteren Grundtvig. (Finn Stein Larsen). . . . . . . .

Bugge, K.E. (ed.):

Grundtvig. Tekstudvalg. (Aa. Jørgensen). . . . . .

84 74-79 (137-138)

Bugge, K. E.:

Grundtvigs skoleverden. (Søren Holm).

$8387-89(100-101)$

$8089-99$ (96)

84 94-99 (142-144)

Dansk Tidsskrift Index:

61. og 62. årg. 1975-76. (Aa. Jørgensen). . . . . . . .

79 74-76

Den Menschen zu gute:

(R. Prenter)

$7258-62(72-73)$

Ehnevid, Tord:

Församlingsetik. (P. G. Lindhardt).

71 111-112 (130-131)

Elbek, Jorgen:

Litteraturen i dag. (W. Michelsen). . . . . . . . . . . .

Grundtvigs atten prøveår. (G. Albeck).

70 89-91 (100)

74 85-86 (94-95)

Ettrup, Flemming og Christensen, Johs. H.:

De Levendes Land. (W. Michelsen).

85 30-91 (103) 
Gjesing, H. B. (red.):

N. F. S. Grundtvig: Om Mennesket i Verden.

(H. Toftdahl). . . . . . . . . . . . .

$8488-89(140)$

Grell, Helge:

Skaberordet og billedordet. (H. Toftdahl). . . . . . .

82 74-86 (95-97)

Grundtvig, N.F.S.:

Grundtvigs Sangværk, I-V. (H. Høirup) . . . . . .

$8466-73$ (137)

Hansen, Uffe:

Grundtvigs salmedigtning. (Kristian Kjær). . . . . .

$6886-88(90)$

Harbsmeier, Götz:

Wer ist der Mensch? (H. Toftdahl). . . . . . . . . .

73 215-217 (234-235)

Henningsen, Bernd:

Die Politik des Einzelnen. (Holberg, Kierkegaard,

Grundtvig). (V. Mortensen). . . . . . . . . . . . . . 77-78 296-298 (309-310)

Henriksen, Aage:

Gotisk tid. (W. Michelsen).

71 120-121 (133-134)

Haarder, Andreas:

Beowulf. The appeal of a poem. (Jens Kruuse). . . .

75 74-80 (84)

Interpreters of Luther.

(V. Mortensen).

71 117-119 (133)

Jorgensen Aage:

Grundtvig til undervisningsbrug. (W. Michelsen).

73 217-218 (235)

Kjar, Holger:

Højskolens Grund. (W. Michelsen).

$7264-69$ (73 236-237)

Knudsen, Johannes (ed.):

En amerikansk Grundtvig-oversættelse. (N. Lyhne

Jensen).

77-78 293-296 (308-309)

Kofoed, Niels:

Myte og intellekt. (W. Michelsen).. . . . . . . . .

70 89-91 (100)

Kontroverse

um Grundtvig und Kierkegaard (H. Toftdahl) . . . .

71 113-117 (131-133)

Kühnhold, Christa:

Der Begriff des Sprunges und der Weg der Sprachdenkens. (H. Toftdahl). . . . . . . . . . . .

$7672-73(75-76)$

Larsen, Ejvind:

Grundtvig og noget om Marx. (Kaj Thaning). . . . .

Det levende ord. (W. Michelsen) . . . . . . . . .

$7486-90(75)$

85 80-87 (138-139) 
Lindhardt, P. G.:

Grundtvigs prædikener i kirkeåret $1854-55 \ldots$ (W. Michelsen). . . . . . . . . . . . . . .

75 69-74 (83-84)

Lundgreen-Nielsen, Flemming (ed.):

N. F. S. Grundtvig: Blik på Poesien og Bernhard Severin Ingemann. (G. Albeck). . . . . . . . . . . . Lyhne Jensen, N. (red.):

A Grundtvig Anthology. Selections from the Writings of N.F.S. Grundtvig (1783-1872). (A. Haarder). . . . . . . . . . . . .

84 87-89 (102-103)

Mortensen, Enok:

Slægtens spor. The Danish Lutheran Church in America. (Johannes Knudsen). . . . . . . . . . . . Schools for Life. (Kaj Thaning).

69 92-95 (105-106) $7966-67$

Nielsen, Frederik:

N. F. S. Grundtvig. Tussiusiai Kalaallisuunngiortitat. (Signe Michelsen).

$8687-90(105)$

Reich, Ebbe:

Frederik. (G. Albeck).

72 65-69 (73 237)

Ritualbog v. Kirkeligt Samfund:

Barnedåb i Kirken og Nadver i Kirken. (Th. Lyby

Christensen). . . . . . . . . . . .

76 65-72 (75)

Skovmand, Roar (ed.):

En Højskolevinter. (Uffe Grosen). . . . . . . . . . . .

$6987-89(105)$

Sneen, Donald Juel:

The Hermeneutics of N. F. S. Grundtvig. (Hejne Simonsen). . . . . . . . . . . .

84 90-93 (140-142)

\section{Thodberg, Christian:}

En glemt dimension i Grundtvigs salmer. (P. G. Lindhardt).

Toftdahl, Hellmut:

Kierkegaard først - og Grundtvig så. (W. Michelsen).

\section{Vartovbogen}

1975-77. (Th. Lyby Christensen). . . . . . . . . . . 
1980. (V. Mortensen). . . . . . . . . . . . . .

$8184-85$

1981. (V. Mortensen)

$8286-89(97)$

1982. Reformation af grundtvigianismen. (V. Mortensen).

83 90-92 (101-102)

1983. (W. Michelsen)

84 100-102 (141-143)

1984. (V. Mortensen)

85 85-86 (102)

1985. (V. Mortensen). . . . . . . . . . . . . . . .

86 94-95 (106)

Egidius, Jens Peter:

Bragesnak. Nordisk myte og myteforskning i dansk tradition. (Vilh. Nielsen) . . . . . . . . . . . . .

85 79-84 (101-102)

Årbog for dansk skolehistorie.

(U. Grosen). . . . . . . . . . . . . . . Aasen, Kirsti:

69 89-92 (105-106)

Alle mine Kilder. (H. Baden Nielsen). . . . . . . .

86 91-95 (106) 